\title{
Mangrove associated macrobenthos community structure from an estuarine island
}

\author{
MD. HABIBUR RAHMAN ${ }^{1}$, M. BELAL HOSSAIN ${ }^{1}$, AHASAN HABIB ${ }^{1,2,3, \bullet}$, MD. ABU NOMAN ${ }^{4}$, \\ SHUVAGATO MONDAL ${ }^{1}$ \\ ${ }^{1}$ Department of Fisheries and Marine Science, Noakhali Science and Technology University. Noakhali-3814, Bangladesh. Tel./fax.: +880-321-71484, \\ vemail: a.habib@umt.edu.my \\ ${ }^{2}$ Faculty of Fisheries and Food Science, Universiti Malaysia Terengganu. 21030 Kuala Nerus, Terengganu, Malaysia \\ ${ }^{3}$ Aquatic Food Security Research Interest Group (RIG), Faculty of Fisheries and Food Science, Universiti Malaysia Terengganu. 21030 Kuala Nerus, \\ Terengganu, Malaysia \\ ${ }^{4}$ College of Marine Science and Technology, China University of Geosciences. 388 Lumo Rd, Hongshan, Wuhan, Hubei, China
}

Manuscript received: 23 August 2020. Revision accepted: 22 December 2020.

\begin{abstract}
Rahman MDH, Hossain MB, Habib A, Noman MDA, Mondal S. 2021. Mangrove associated macrobenthos community structure from an estuarine island. Biodiversitas 22: 247-252. Macroinvertebrate living on or around the mangroves has not been or less investigated in Bangladesh. This study was carried out to describe the density, distribution, and community structure of mangrove associated macrobenthos in Nijhum Dwip, central coast of Bangladesh. A total of 17 taxa were identified belonging to mainly Polychaetes (67.37\%), Mysids (23.53\%), Isopods (3.83\%), Amphipods (0.58\%), and Gastropods (0.29\%). Polychaetes were dominant by contributing $67.37 \%$ of total macrobenthos. The number of benthic fauna ranged from 359 to $1617 \mathrm{inds} . / \mathrm{m}^{2}$ with a mean value of $1003.93 \pm 400.3 \mathrm{inds} . / \mathrm{m}{ }^{2} \mathrm{There}$ was no significant difference observed $(p>0.05)$ in the abundance of macrofauna among the stations. The maximum Shannon-Wiener Index $\left(\mathrm{H}^{\prime}\right)$ of species diversity was found at St2 (1.323) and the lowest at St4 (0.8) in the monsoon period possibly due to high rainfall and disturbance of benthic habitat. The Shannon-Wiener diversity values suggest the area was less polluted. The information from the present study can be used to measure the impacts of pollution to conserve biodiversity in sustainable manner.
\end{abstract}

Keywords: Estuarine island, macrobenthos, mangrove ecosystem, Nijhum Dwip, Bangladesh

\section{INTRODUCTION}

The coastal vegetated wetlands such as mangroves, seagrass beds, and salt marshes account for $<0.2 \%$ of the total ocean area and have been considered as most productive ecosystems in the world ( $\mathrm{Su}$ et al. 2020). Mangrove ecosystems normally occur in sheltered locations along the coastline. In optimum condition mangrove ecosystem develops into a large productive forest (Loughland et al. 2020). In addition, mangroves play an important role worldwide serving as unique and vital ecosystems connecting the land and sea in tropical and subtropical coastal regions ( $\mathrm{Li}$ et al. 2017). They provide shelter, food, breeding sites for marine organisms, and ecosystem services on which coastal people depend on their livelihood, and for their socioeconomic development (Lee et al. 2014; Chen et al. 2015). These ecosystems provide diverse ecological benefits including supporting high biodiversity and ecosystem service functions (Luo et al. 2010; Su et al. 2020). Due to their effects on biodiversity and productivity of macrofauna, estuarine and marine ecosystems also serve as nursery grounds for ecologically and economically important marine species (Bertelli and Unsworth 2014). However, the increased anthropogenic activities in the coastal regions also produced adverse effects on marine life and disturb the coastal environment particularly mangrove ecosystem (Farooq and Siddiqui 2020). Bangladesh coastline is also prone to various natural disasters such as cyclones, river erosion, salinity intrusion, floods, high population density, and poor socio-economic conditions. The Sundarbans is the biggest mangrove forest in Bangladesh, which is used as strengthen of coastal forest (Iftekhar and Takama 2008). Different mangrove communities support different macrobenthic faunal communities (Samidurai et al. 2011; Chen et al. 2015). The sediment differs among mangrove communities, which has great effects on diversity indices (richness, evenness) of macrobenthic fauna (Alfaro 2010; Chen et al. 2015; Leung 2015). In addition, variation in species diversity and population of benthic organisms reflects the environmental composition and condition in specific wetland (Leung and Cheung 2017). Research on community structure of macrobenthic fauna in mangrove areas might provide valuable information on management, restoration, and sustainable use (Chen et al. 2015). Thus, it follows the community structure of macrobenthos in an estuarine island and/or changes in a mangrove forest succession.

Like other estuarine islands, the Nijhum Dwip island occupies large area of mangroves including mudflats, tidal creeks with high level of biodiversity (Asadujjaman et al. 2012). This island is under Hatiya Upazila and Noakhali District, Bangladesh. The island began to form in the $1950 \mathrm{~s}$, at present the total area of the island is 4,057 ha and the soil is mainly undeveloped with little development of Meghna alluvial deposits. The surface soil is primarily 
medium-textured silt loam and poor in organic matter. However, the ecosystem appears to be declining phase due to ecological and climate change (Iftekhar and Takama 2008). Mangrove ecosystems are at high risk around the world despite their unique properties and ecological functions ( $\mathrm{Li}$ et al. 2017). Like any other ecosystem in the world, these resources also have been declining due to human activities particularly deforestation, overexploitation, illegal fishing, improper waste management, pollution, and other anthropogenic activities (Adeel and Pomeroy 2002). All of these caused serious threats to marine biodiversity. If this current trend of environmental degradation continues then marine ecosystem will be irreversible, damaged, and finally leading to resource depletion (Olomukoro and Azubuike 2009). In Bangladesh mangrove ecosystems also under high risk due to population boom, rapid economic development in aquaculture, agriculture, industry, and urban construction. Bangladesh coastline is very vulnerable and quite sensitive to coastal erosion due to climate change (Habib 2010). Therefore, it is very important to understand the pattern of species biodiversity distribution, and in recent years ecologists have given more attention to it as well (Yunandar et al. 2020).

Macrobenthic organisms are the most important permanent residents in the coastal wetlands. They used to monitor the effects of organic enrichment, various types of aquatic pollution, and anthropogenic influences, because of their sedentary life-patterns, distribution, and abundance (Farooq and Siddiqui 2020). In addition, they also act as bio-indicator for environmental monitoring (Farooq and Siddiqui 2020), which can be reliably used for the classification of coastal areas, rivers, and the state of the ecosystems (Hatami et al. 2017; Tania et al. 2020). Longlife cycles of macrobenthic organisms allow ecologists to determine any decline in environmental quality, which could be assessed by studying the population responses of the coastal zoo benthos and the effects on the coastal biodiversity (i.e., organisms community composition, structure, and subsequent functioning. Thus, the study of benthic organisms and their community structure is important (Noman et al. 2019). Some previous researches were conducted on macrobenthic community from Bangladesh coastal waters such as estuarine macrophytes diversity in mangrove in Cox's Bazar (Abu Hena et al. 2013), occurrence and abundance of macrobenthos in Hatiya and Nijhum Dwip (Asadujjaman et al. 2012), diversity of fish fauna and their status, conservation (Ali et al. 2014), seasonal and spatial distribution of macrozoobenthos from Meghna river estuary (Hossain et al. 2009), intertidal macrobenthic fauna and their relations with environmental variables in Karnafuli estuary (Islam et al. 2013), diversity, distribution, and abundance of benthos in Mouri river, Khulna, Bangladesh (Khan et al. 2007), recent study on cage culture effects on macrobenthic community in Dakatia river (Tania et al. 2020), and spatial and seasonal distribution of intertidal macrobenthos with their biomass and functional feeding guilds in Naf river estuary Bangladesh (Noman et al. 2019). However, none of the previous studies have focused on mangrove-associated macrofauna. Therefore, the specific aim of the present study was to describe the abundance, distribution, and community structures of macro invertebrates that were living on mangroves or in the sediment adjacent to mangroves.

\section{MATERIALS AND METHODS}

\section{Study area}

The present study was conducted from the Nijhum Dwip Island, which is situated in the southern part of Bangladesh. It is a mangrove intertidal zones where continuous high tides and low tides have fluctuated. The study was conducted in the monsoon season (July to September) in 2017. Five stations were selected from around the Nijhum Dwip Island, Bangladesh (Figure 1). These stations are, station 1 (St1) Char Usman $\left(22^{\circ} 02^{\prime} 24.239 \mathrm{~N}, \quad 90^{\circ} 58^{\prime} 41.274 \mathrm{E}\right), \quad$ station $2 \quad(\mathrm{St} 2)$ Batayeenguscho gram $\left(22^{\circ} 02^{\prime} 34.012^{\prime \prime} \mathrm{N}, 90^{\circ} 58^{\prime} 53.406 \mathrm{E}\right)$, station $3 \quad(\mathrm{St} 3) \quad$ Murkhali $\left(22^{\circ} 02^{\prime} \quad 41.581^{\prime \prime} \mathrm{N}\right.$, $\left.90^{\circ} 58^{\prime} 57.293 \mathrm{E}\right)$, station 4 (St4) Jatrakhali $\left(22^{\circ} 02^{\prime} 24.274 " \mathrm{~N}\right.$, $\left.90^{\circ} 58^{\prime} 44.192 \mathrm{E}\right), \quad$ station $5 \quad$ (St5) Chorakhali $\left(22^{\circ} 02^{\prime} 19.015^{\prime \prime} \mathrm{N}, 90^{\circ} 58^{\prime} 21.138^{\prime \prime} \mathrm{E}\right)$. Stations were selected based on the presence of mangroves and low anthropogenic activities. Samplings were performed three times from each station and total of fifteen times from the sampling sites.

\section{Sample collection, sieving, sorting, and identification}

Benthos was collected using Eijkman Dredge having a mouth opening of $0.01 \mathrm{~m}^{2}$ (dimension: $10 \mathrm{~cm} \times 10 \mathrm{~cm}$ $\times 10 \mathrm{~cm}$ ). Samples were collected from the intertidal zones during the low tides from around the Island. Five replicates samples were collected from each station. The sediment samples were transferred from polyethylene bag to bucket and washed with clean water, then hand-sieved through 0.5 $\mathrm{mm}$ mesh to get the macrobenthos. The sieved organisms and residues were immediately preserved with $10 \%$ formalin solution in plastic container with labeling until further analysis. To increase the visibility of benthic infauna small amount of Rose Bengal was added to the formalin solution of the plastic container. Macrobenthos were separated manually in a tray under enough light availability. Samples were counted and calculated for total amount of inds. $/ \mathrm{m}^{2}$. Then the sorted samples were preserved into $70 \%$ alcohol solution in small vials for identification.

\section{Data analysis}

The diversity of benthic fauna and one-way ANOVA were performed using PAST version 3.10 (Hammer et al. 2001). Shapiro-Wilk test and Levene's test of homogeneity in terms of ANOVA were performed to analyze the normality and homogeneity of the variance. Data were transformed square root before further analysis when the data showed skewness One-way ANOVA was performed to test the hypothesis whether there was significant difference among the stations at the $95 \%$ confidence level. 


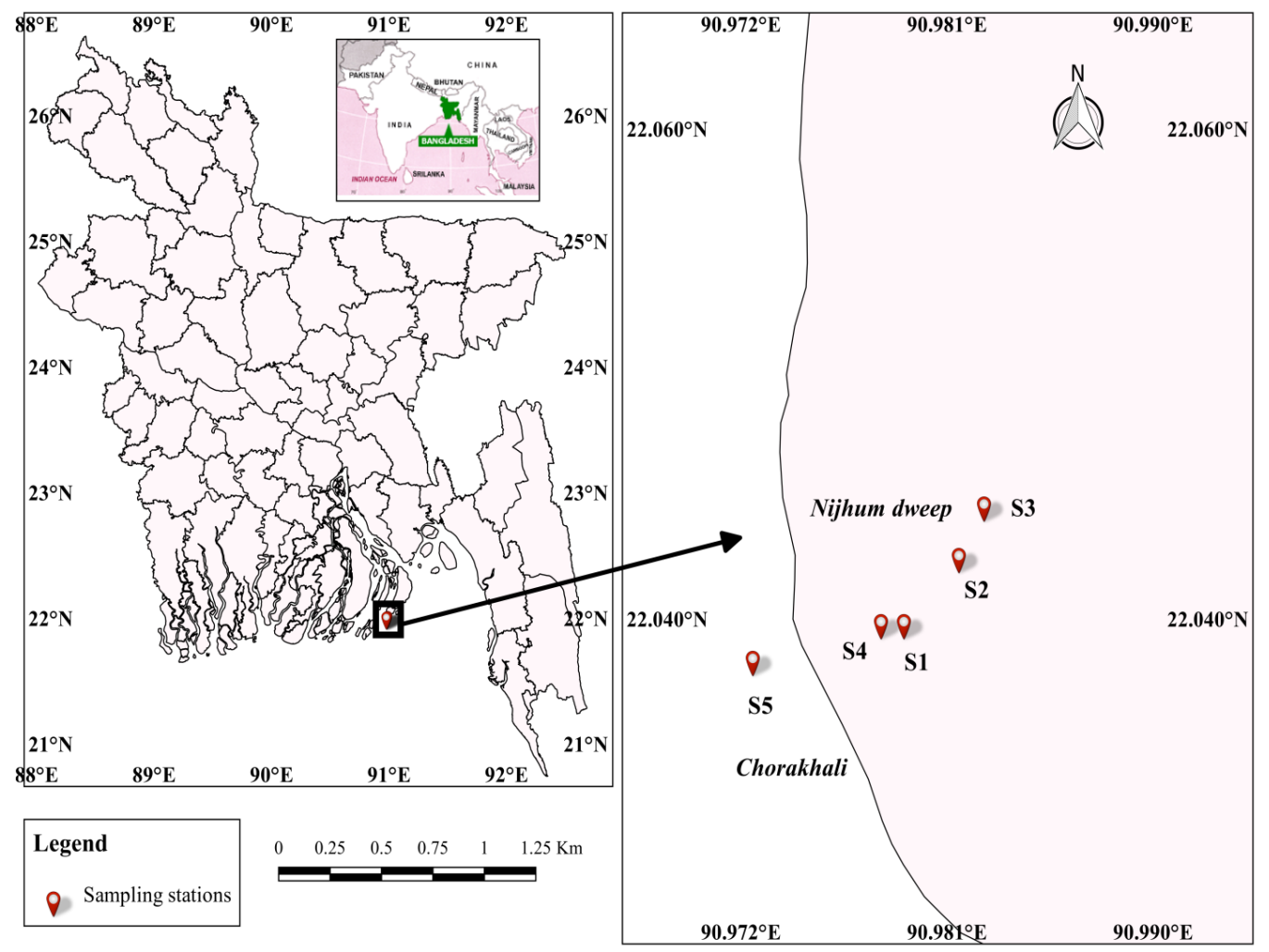

Figure 1. Map of the study region with the sampling sites in Nijhum Dwip Island, Bangladesh indicated by St1 to St5

\section{RESULTS AND DISCUSSION}

\section{Abundance of macrobenthos taxa}

In the present study, a total number of 17 taxa of macroinvertebrate infauna and a total number of 5292 inds. $/ \mathrm{m}^{2}$ was found from all stations during the study period (Table 1). The number of benthic infauna in the present study ranges from 359 to 1617 inds. $/ \mathrm{m}^{2}$ (Table 1 ). The highest numbers of individuals were found at $\mathrm{St} 2$ (1617 inds. $/ \mathrm{m}^{2}$ ) and the lowest number of benthos were (359 inds. $/ \mathrm{m}^{2}$ ) found at $\mathrm{St} 5$. The average density of the present study was $1003.93 \pm 400.3$ inds. $/ \mathrm{m}^{2}$ (Table 1). Asadujjaman et al. (2012) studied the abundance of macrobenthos and found the density of macrobenthos ranged between 4511 inds. $/ \mathrm{m}^{2}$ to 433 ind. $/ \mathrm{m}^{2}$ in Hatiya and Nijhum Dwip island. Khan et al. (2007) recorded the average density of benthos $630-1040$ inds. $/ \mathrm{m}^{2}$ in Mouri river, Khulna which was supports the result of the present study. Tania et al. (2020) also reported huge number of macrobenthos in monsoon reason. However, St3 showed less abundance of macrobenthic community in the present study, this might be the result of fishing, and tourism activities. Human intervention might be the reason for discrimination of abundance of macrobenthos (Noman et al. 2019).

\section{Abundance of taxonomic groups}

The group of Polychaeta (3644 inds. $/ \mathrm{m}^{2}$ ) infauna were identified from the study area during monsoon period as the most abundant group while Gastropoda (15inds. $/ \mathrm{m}^{2}$ ) and Hirunida $\left(15\right.$ inds. $/ \mathrm{m}^{2}$ ) were found least abundant group (Table 2). In the present study, 10 genera of macrobenthos were recorded whereas 5 macrobenthic groups were mostly dominated namely Polychaeta, Gastropoda, Mysida, Isopoda, and Amphipoda (Table 2). The result has more or less similar to the findings of Hossain et al. (2009), Asadujjaman et al. (2012), Hossain et al. (2013), and Noman et al. (2019). In addition, Raja et al. (2014) and $\mathrm{Xu}$ et al. (2016) reported that Polychaetes formed the largest group among all groups of taxa, which supported the results of the present study. The difference between the present study and those studies is that no Oligochaetes were found in the present study. However, we hypothesize, this may indicate that studied areas are still unpolluted. Lin and Yo (2008) investigated that aquatic Oligochaetes are abundant in polluted areas, which commonly used as bioindicator to study pollution in rivers and streams (Lin and Yo 2008).

\section{Diversity indices}

The station-wise diversity indices, number of taxa (S), number of individuals, Dominance (D), Shannon-Wiener diversity index $\left(\mathrm{H}^{\prime}\right)$, and Margalef richness index $\left(\mathrm{J}^{\prime}\right)$ value are presented in Table 3. Shanon-Wiener diversity ( $\left.H^{\prime}\right)$ index value of benthic infauna ranged from 0.8 to 1.323 (Table 3). The Shanon-Wiener ( $\left.\mathrm{H}^{\prime}\right)$ index value from Khan et al. (2007) and Sarker et al. (2016) was almost close to the present study. However, Pawar (2015) reported a very low diversity value $(0.203$ to 0.332$)$ from the heavily polluted area which reveals that macrobenthic community 
was under stress conditions. Besides, another study revealed that higher cadmium concentration in the sediment leads to lower diversity $\left(\mathrm{H}^{\prime}\right)$ of infaunal community (Leung and Tam 2013). Unlike aforementioned studies, the diversity value of our study was not very low to predict the influence of pollution. The Margalef richness $(\mathrm{J})$ richness diversity of the present study ranged from 0.245 to 0.630 . This result showed a difference from the findings of Sarker et al. (2016). This difference is mainly due to the variation of salinity, sediment condition, and contamination factor. Noman et al. (2019) also reported that inconsistent results might occur due to variation in ecological characteristics (water parameters, sediment characteristics, grain size, organic content, habitat condition, and anthropogenic factors).

Table 1. Total benthic family (inds. $/ \mathrm{m}^{2}$ ) found in the study period

\begin{tabular}{lcccccccc}
\hline \multicolumn{1}{c}{ Name of the taxa } & St1 & St2 & St3 & St4 & St5 & Mean \pm SD & Total & Average percentage $(\%)$ \\
\hline Nereididae 1* & 163 & 356 & 30 & 637 & 355 & $308.13 \pm 93.47$ & 1541 & 30.6 \\
Nereididae 2* & 89 & 326 & 30 & 518 & 163 & $225.13 \pm 60.19$ & 1126 & 22.36 \\
Nephtyidae* & 163 & 15 & 30 & 0 & 59 & $53.27 \pm 19.97$ & 267 & 5.29 \\
Eunicidae & 25 & 30 & 0 & 0 & 0 & $20.73 \pm 15.55$ & 55 & 2.06 \\
Glyceridare & 0 & 30 & 30 & 0 & 15 & $14.73 \pm 7.06$ & 75 & 1.46 \\
Goniadidae & 0 & 445 & 0 & 0 & 0 & $29.67 \pm 24.05$ & 445 & 2.95 \\
Nemanerididae & 30 & 0 & 0 & 0 & 60 & $17.8 \pm 12.88$ & 90 & 1.77 \\
Lumbrinidae & 0 & 0 & 45 & 0 & 0 & $8.87 \pm 6.43$ & 45 & 0.88 \\
Isopoda & 0 & 0 & 119 & 0 & 74 & $38.53 \pm 27.06$ & 193 & 3.83 \\
Mysid & 356 & 385 & 15 & 15 & 415 & $236.93 \pm 100.32$ & 1186 & 0.83 \\
Crab larvae & 45 & 0 & 0 & 0 & 0 & $8.87 \pm 8.87$ & 45 & 2.05 \\
Shrimp larvae & 74 & 0 & 15 & 0 & 15 & $20.67 \pm 12.17$ & 104 & 0.29 \\
Hisonidae & 0 & 0 & 15 & 0 & 0 & $2.93 \pm 2.93$ & 15 & 0.58 \\
Amphipoda & 0 & 15 & 15 & 0 & 0 & $5.87 \pm 3.99$ & 30 & 0.29 \\
Hirunidae & 0 & 0 & 15 & 0 & 0 & $0 \pm 00$ & 15 & 0.88 \\
Insect larvea & 0 & 15 & 0 & 0 & 30 & $8.87 \pm 6.43$ & 45 & 100 \\
Gastropoda & 0 & 0 & 0 & 15 & 0 & $2.93 \pm 2.93$ & 15 & 0.29 \\
Total & 945 & 1617 & 359 & 1185 & 1186 & $1003.93 \pm 400.3$ & 5292 & \\
\hline Nil & & & & & & & \\
\end{tabular}

Note: St: Station

Table 2. Abundance of taxonomic groups (inds. $/ \mathrm{m}^{2}$ ) found at the study period

\begin{tabular}{lcccc}
\hline \multicolumn{1}{c}{ Group } & Mean \pm SD & Total & Average percentage $(\%)$ & Rank \\
\hline Polychaeta & $678.33 \pm 239.6$ & 3644 & 67.37 & 1 \\
Gastropoda & $2.93 \pm 2.93$ & 15 & 0.29 & 7 \\
Amphipoda & $5.87 \pm 3.99$ & 30 & 0.58 & 6 \\
Isopoda & $38.53 \pm 27.06$ & 193 & 3.83 & 3 \\
Mysida & $236.93 \pm 100.32$ & 1186 & 23.53 & 2 \\
Crab larvae & $8.87 \pm 8.87$ & 45 & 0.88 & 5 \\
Shrimp larvae & $20.67 \pm 12.17$ & 104 & 2.05 & 7 \\
Hirunidae & $0 \pm 00$ & 15 & 0.29 & 5 \\
Insects larvae & $8.87 \pm 6.43$ & 45 & 0.88 & 7 \\
Hisonidae & $2.93 \pm 2.93$ & 15 & 0.29 & \\
\hline
\end{tabular}

Table 3. Diversity indices observed in the present study

\begin{tabular}{lccccc}
\hline \multicolumn{1}{c}{ Parameters } & St1 & St2 & St3 & St4 & St5 \\
\hline Taxa (S) & 4 & 6 & 5 & 3 & 5 \\
Individuals (Total) & 993 & 1319 & 355 & 1185 & 1184 \\
Dominance (D) & 0.385 & 0.326 & 0.607 & 0.478 & 0.521 \\
Shannon-Wiener (H') & 1.14 & 1.323 & 1.274 & 0.8 & 0.985 \\
Evenness (E') & 0.8 & 0.714 & 0.867 & 0.826 & 0.747 \\
Margalef richness (J') & 0.436 & 0.603 & 0.63 & 0.245 & 0.389 \\
\hline
\end{tabular}

Note: St: Station 


\section{Pollution indicator groups}

The Polychaeta community is generally being used for the status of the benthic environment (Dean 2008; Hossain et al. 2020). Among them, the presence of positive indicator group denotes the poor environmental condition and the absence of negative indicator groups prevail the detrimental environmental (Belan et al. 2013; Hossain et al. 2020). The capetillids (especially Capitella capitate) are well known positive indicator groups which were not found in our study region. Besides, along this coastline, a recent study of Hossain et al. (2020) found the negative indicator taxa Nerididae and Nephtyide had higher abundance in the unpolluted site than the reference site. Similarly, in our study Nerididae and Nephtyide were the most dominant taxa that may denote the non-polluted environment.

In conclusion, the species diversity and the pollution indicator taxa of the present study areas revealed that all stations of the study were less polluted during the study period. The obtained information can be used for further analysis to compare the pollution status using macrobenthos in this area, and conservation of macrobenthos biodiversity. However, a long-term study focusing on macrobenthos and sediment parameters is recommended to further in-depth quantification of the pollution in this area.

\section{ACKNOWLEDGEMENTS}

The authors would like to thank fishermen in Nijhum Dwip Island and lab technician of FIMS, NSTU.

\section{REFERENCES}

Abu Hena M, Sidik JB, Aysha A, Ahasan H, Short F. 2013. Estuarine macrophytes at Bakkhali, Cox's Bazar, Bangladesh with reference to mangrove diversity. Chiang Mai J Sci 40 (4): 556-563.

Adeel Z, Pomeroy R. 2002. Assessment and management of mangrove ecosystems in developing countries. Trees 16 (2-3): 235-238.

Alfaro AC. 2010. Effects of mangrove removal on benthic communities and sediment characteristics at Mangawhai Harbour, northern New Zealand. ICES J Mar Sci 67 (6): 1087-1104.

Ali MM, Hossain MB, Rahman M, Habib A. 2014. Diversity of fish fauna in the Chitra river of Southwestern Bangladesh: present status, threats and recommendations for conservation. Asian J Appl Sci 7 (7): 635643.

Asadujjaman M, Hossain MB, Shamsuddin M, Amin MA, Azam AKM 2012. Occurrence and abundance of macrobenthos of Hatiya and Nijhum Dweep Islands, Bangladesh. Middle-East J Sci Res 11 (2): 184-188.

Belan TA. 2013. Peculiarities of distribution of taxocenes of polychaete worms (Polychaeta) in Amursky Bay (the Sea of Japan) in the early 21st century. Pac Oceanogr 6: 64-71.

Bertelli CM, Unsworth RKF. 2014. Protecting the hand that feeds us: Seagrass (Zostera marina) serves as commercial juvenile fish habitat. Mar Pollut Bull 83 (2): 425-429.

Chen Q, Li J, Zhang L, Lu H, Ren H, Jian S. 2015. Changes in the macrobenthic faunal community during succession of a mangrove forest at Zhanjiang, South China. J Coast Res 31 (2): 315-325.

Dean HK. 2008. The use of polychaetes (Annelida) as indicator species of marine pollution: A review. Rev Biol Trop 56: 11-38. DOI: 10.15517/RBT.V56I4.27162.

Farooq S, Siddiqui PJ. 2020. Assessment of three mangrove forest systems for future management through benthic community structure receiving anthropogenic influences. Ocean Coast Manag 190: 105162. DOI: $10.1016 /$ j.ocecoaman.2020.105162
Habib A. 2010. Possible Economic Impact on Coastal Fish Stock Resources in Bangladesh in the Case of Climate Change. [Master Thesis]. University of Tromso, Norway.

Hammer $\emptyset$, Harper DA, Ryan PD. 2001. PAST: Paleontological statistics software package for education and data analysis. Palaeontologia Electronica 4 (1): 1-9.

Hatami R, Paul W, Soofiani NM, Asadollah S. 2017. Rapid bioassessment of macroinvertebrate communities is suitable for monitoring the impacts of fish farm effluents. Aquac 468: 19-25. DOI: 10.1016/j.aquaculture.2016.09.042

Hossain MB, Das N, Sharmeen R. 2009. Seasonal and spatial distribution of macrozoobenthos of the Meghna River estuarine bed. Int J Sustain Agri Technol 5 (3): 11-16.

Hossain MB, Amin S, Asadujjaman M, Rahman S. 2013. Analyses of macrobenthos of Hatiya and Nijhum Dweep Islands at higher taxonomic resolution. J Fish Aquat Sci 8 (4): 526-534.

Hossain MB, Noman MA, Lipi JA, Kamal AH, Idris MH. 2020. Effects of ship-breaking activities on the abundance and diversity of macrobenthos in Sitakundu Coast, Bangladesh. Biodiversitas 21 (11): 5085-5093. DOI: 10.13057/biodiv/d211113

Iftekhar M, Takama T. 2008. Perceptions of biodiversity, environmental services, and conservation of planted mangroves: a case study on Nijhum Dwip Island, Bangladesh. Wetl Ecol Manag 16 (2): 119-137.

Islam MS, Sikder MNA, Al-Imran M, Hossain MB, Mallick D, Morshed MM. 2013. Intertidal macrobenthic fauna of the Karnafuli estuary: Relations with environmental variables. World Appl Sci J 21 (9): 1366-1373.

Khan A, Kamal D, Mahmud M, Rahman M, Hossain M. 2007. Diversity, distribution, and abundance of benthos in Mouri River, Khulna, Bangladesh. Int J Sustain Crop Product 2 (5): 19-23.

Lee SY, Primavera JH, Dahdouh-Guebas F, McKee K, Bosire JO, Cannicci S, Diele K, Fromard F, Koedam N, Marchand C, Mendelssohn I. 2014. Ecological role and services of tropical mangrove ecosystems: A reassessment. Glob Ecol Biogeogr 23 (7): 726-743. DOI: $10.1111 /$ geb.12155

Leung JYS, Tam NF. 2013. Influence of plantation of an exotic mangrove species, Sonneratia caseolaris (L.) Engl., on macrobenthic infaunal community in Futian Mangrove National Nature Reserve, China. J Exp Mar Biol Ecol 448: 1-9. DOI: 10.1016/j.jembe.2013.06.006

Leung JYS. 2015. Habitat heterogeneity affects ecological functions of macrobenthic communities in a mangrove: Implication for the impact of restoration and afforestation. Glob Ecol Conserv 4: 423-433. DOI: 10.1016/j.gecco.2015.08.005

Leung, JYS, Cheung, NKM. 2017. Can mangrove plantation enhance the functional diversity of macrobenthic community in polluted mangroves? Mar Pollut Bull 116 (1-2): 454-461.

Lin K-J, Yo S-P. 2008. The effect of organic pollution on the abundance and distribution of aquatic oligochaetes in an urban water basin, Taiwan. Hydrobiologia 596 (1): 213-223.

Li Y-F, Du F-Y, Gu Y-G, Ning J-J, Wang L-G. 2017. Changes of the macrobenthic faunal community with stand age of a non-native mangrove species in Futian Mangrove National Nature Reserve, Guangdong, China. Zool Stud 56 (19). DOI:10.6620/ZS.2017.56-19.

Loughland R, Butt SJ, Nithyanandan M. 2020. Establishment of mangrove ecosystems on man-made islands in Kuwait: Sustainable outcomes in a challenging and changing environment. Aquat Bot 167: 103273. DOI: $10.1016 /$ j.aquabot.2020.103273

Luo ZK, Sun JX, Xu HL. 2010. A comparison of species composition, stand structure between planted, natural mangrove forests in Shenzhen Bay, South China. J Plant Ecol 3 (3): 165-174.

Noman MA, Mamunur R, Islam MS, Hossain MB. 2019. Spatial and seasonal distribution of intertidal macrobenthos with their biomass and functional feeding guilds in the Naf River estuary, Bangladesh. J Oceanol Limnol 37 (3): 1010-1023.

Olomukoro JO, Azubuike CN. 2009. Heavy metals and macroinvertebrate communities in bottom sediment of Ekpan Creek, Warri, Nigeria. Jordan J Biol Sci 2 (1): 1-8.

Pawar PR. 2015. Monitoring of pollution using density, biomass and diversity indices of macrobenthos from mangrove ecosystem of Uran, Navi Mumbai, West Coast of India. J Bioremed Biodeg 1 (4): 136145. DOI: 10.4172/2155-6199.1000299

Raja M, Ramkumar R, Perumal P. 2014. Diversity, distribution, threats and conservation action of fish fauna in Chinnar Reservoir, Tamil Nadu. J Res Biol 4 (3): 1317-1327. 
Samidurai K, Saravanakumar A, Kathiresan K. 2011. Spatial and temporal distribution of macrobenthos in different mangrove ecosystems of Tamil Nadu Coast, India. Environ Monit Assess 184 (7): 4079-4096.

Sarker M, Patwary S, Uddin A, Md HM, Tanmay M. 2016. Macrobenthic community structure-an approach to assess coastal water pollution in Bangladesh. Fish Aquac J 7: 157. DOI: 10.4172/2150-3508.1000157

Su Z, Qiu G, Fan H, Fang C. 2020. Seagrass beds store less carbon but support more macrobenthos than mangrove forests. Mar Environ Res 162:105162. DOI: 10.1016/j.marenvres.2020.105162.
Tania NJ, Hossain MB, Habib A, Musa N. 2020. Effects of fish cage culture on macrobenthic communities in a subtropical river. Biodiversitas 21 (8): 3583-3589. DOI: 10.13057/biodiv/d210822

Xu Y, Li X, Wang H, Zhang B. 2016. Seasonal and spatial variations of macrobenthic community structure and diversity in the South Yellow Sea. Aquat Ecosyst Health Manag 19 (1): 92-100.

Yunandar D, Effendi H, Setiawan Y. 2020. Plankton biodiversity in various typologies of inundation in Paminggir peatland, South Kalimantan, Indonesia on dry season. Biodiversitas 21 (3): 10121019. DOI: $10.13057 /$ biodiv/d210322. 